\title{
Desarrollo Y Simulación De Un Modelo De Transceptor Basado En Prime Para Simulación Sobre Canal PLC
}

\author{
Jorge E. Veglia, \\ David L. La Red Martinez,
}

Facultad de Ciencias Exactas, Naturales y Agrimensura, Departamento de Informática, Universidad Nacional del Nordeste, Corrientes, Argentina

\section{Reinaldo J.R. Scappini,}

Facultad Regional Resistencia, Departamento de Ingeniería en Sistemas de Información, Universidad Tecnológica Nacional, French Resistencia, Chaco

Doi: 10.19044/esj.2018.v14n27p229 URL:http://dx.doi.org/10.19044/esj.2018.v14n27p229

\begin{abstract}
The choice of modification technique for a communications system depends to a large extent on the nature and characteristics of the medium in which it must operate (Hrasnica et al., 2005). In a PLC (Power Line Communications) system, the first applications in the LDR band (oriented to the control of devices) operated with monocarrier modulations, such as ASK, BPSK, and FSK. This allows for low implementation costs, provided that it operates at low data rates and with an error correction system. It is clear that applications require a higher data rate. The modulation technique must overcome challenges such as the necessary equalization for the cause of the non-linearity of the channel, or avoid the propagation delays and the multipath caused by the impedance differences in the branches. Likewise, it must offer flexibility and avoid the use of certain frequencies if they are altered or assigned to another service and, therefore, cannot be used in PLC. In this scenario, one of the techniques that have been imposed in the most used developments in NB-PLC as in BB-PLC has been Orthogonal Frequency Division Multiplexing (OFDM). One of its most attractive aspects from the point of view of its complexity is the possibility of implementing the structure of its multifrequency modulation and demodulation scheme through a simple Inverse Discrete Fourier Transform (IDFT) and its corresponding direct transform, Fast Fourier Transform (FFT). Based on this technique, an appropriate transceiver scheme for operating on a PLC channel model was presented. This development implements the error correction technique proposed for NB-PLC.
\end{abstract}


Keywords: AMI, intelligent networks, PLC channels, OFDM, Simulation, Matlab/ Simulink

\section{Resumen}

La elección de la técnica de modificación para un sistema de comunicaciones depende en gran medida de la naturaleza y características del medio en el que tiene que operar (Hrasnica et al., 2005). En un sistema PLC (Power Line Communications), las primeras aplicaciones en la banda LDR (orientadas al control de dispositivos), operaban con modulaciones monoportadoras, como ASK, BPSK y FSK. Esto permite bajos costos de implementación, siempre que opere a bajas velocidades de datos y con un sistema de corrección de errores. Está claro que las aplicaciones requieren una mayor velocidad de datos. La técnica de modulación debe superar desafíos tales como la ecualización necesaria por causa de la no linealidad del canal, o evitar los retrasos de propagación y multitrayecto causado por las diferencias de impedancia en las ramificaciones. Asimismo, debe ofrecer flexibilidad y evitar el uso de ciertas frecuencias si están muy alteradas o si están asignadas a otro servicio, y por lo tanto no pueden utilizarse en PLC. En este escenario, una de las técnicas que se ha impuesto a los desarrollos más utilizados en NB-PLC como en BB-PLC ha sido la multiplexación por división de funciones ortogonales (OFDM). Uno de sus aspectos más atractivos desde el punto de vista de su complejidad es la posibilidad de implementar la estructura de su esquema de demodulación y modulación multifrecuencia a través de una simple transformación inversa directa de Fourier (IDFT) y su correspondiente transformación directa (FFT). Basado en esta técnica, se presenta un esquema de transceptor apropiado para operar en un modelo de canal PLC. Este desarrollo implementa la técnica de corrección de errores propuesta para NB-PLC.

Palabras clave: AMI, redes inteligentes, canales PLC, OFDM, Simulación, Matlab/Simulink

\section{Introduction}

El trabajo se estructura repasando las generalidades y fundamentos de la modulación OFDM FFT, y aspectos particulares como los mecanismos utilizados para evitar las interferencias inter-símbolo (ISI) e inter-portadora (ICI), las técnicas de codificación diferencial y no diferencial y otros. A continuación, se analiza una técnica de procesamiento que ha recibido atención en varias investigaciones e incluso ha sido implementada en algunas especificaciones que utilizan OFDM en canales inalámbricos, como lo es la transformada Wavelet. Se analizan las ventajas reportadas respecto del 
procesado mediante FFT, y su aplicabilidad a los actuales estándares utilizados en NB-PLC. Posteriormente, se resumen los aspectos y parámetros más salientes de una de las especificaciones más difundidas en las soluciones comerciales y la bibliografía, PRIME, la que se toma como referencia para el modelo con el que se realiza y simula en Matlab/Simulink. Finalmente, se vuelcan los comentarios y discusiones más significativos.

\section{Fundamentos}

\subsection{La modulación OFDM - FFT}

La modulación multi portadora (Multi Carrier Modulation, MCM) utiliza el principio de dividir un flujo de datos a transmitir en varias canales de bits paralelos, cada uno de los cuales tiene una tasa de bits mucho más baja, y modular cada uno mediante una portadora distinta, llamada subportadora. OFDM es una forma especial de MCM, con subportadoras y espectros en frecuencia superpuestos espaciados densamente, como en la Figura 1. Esto se logra haciendo que las subportadoras sean ortogonales entre sí, es decir, que los espectros de cada una en particular sean nulos en los máximos de las otras. De este modo se asegura que no exista interferencia entre ellas sin necesidad de una banda de separación entre las mismas. Ocupando el mismo ancho de banda de una señal monoportadora, un conjunto OFDM proporciona una mejor respuesta que ésta a los canales dispersivos en el tiempo, ya que el retardo por multitrayecto constituye una fracción del mismo considerablemente más corta que en el caso de los sistemas convencionales serie; asimismo, ante la existencia de ruido impulsivo o muescas profundas en la respuesta en frecuencia en el canal, el sistema OFDM únicamente se ve afectado durante una fracción de la duración de los símbolos transmitidos en paralelo (al transmitir información en $\mathrm{N}$ subportadoras, la duración del símbolo de una señal OFDM es $\mathrm{N}$ veces mayor que la duración del símbolo de una señal de portadora única equivalente), permitiendo su recuperación mediante sistemas correctores de error más simples (Hrasnica et al., 2005).

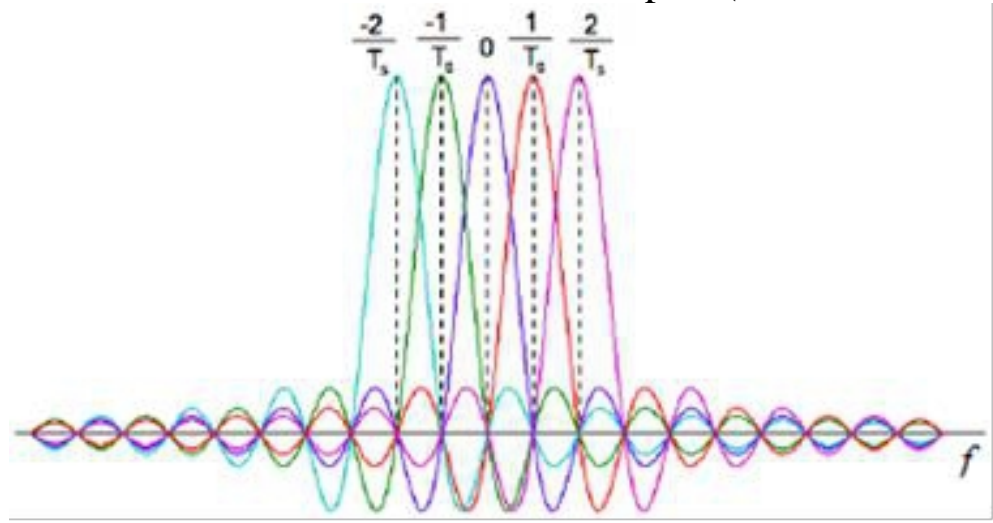

Figura 1. Espectro en frecuencia de una señal OFDM (Propio) 


\subsubsection{Moduladores y demoduladores OFDM - FFT}

Los bits de información pasan por el proceso de "mapeo", conformando símbolos de acuerdo a la modulación en banda base utilizada (M-QAM, M-PSK, etc.), con una cantidad de bits por símbolo $\mathrm{M}$ igual a una potencia de 2. Cada símbolo, con una componente real y otra compleja y con una duración fija $T_{s}$, se asigna a una subportadora. Como la condición de ortogonalidad implica que la separación espectral de éstas sea $\Delta f=1 / T_{s}$. un modulador OFDM puede construirse mediante un conjunto de osciladores tal como se representa en la Figura 3.2, en el que se modulan $N_{c}$ símbolos mediante un banco de igual número de osciladores de frecuencias $f_{k}$, tales que $f_{k}=k \Delta f$.

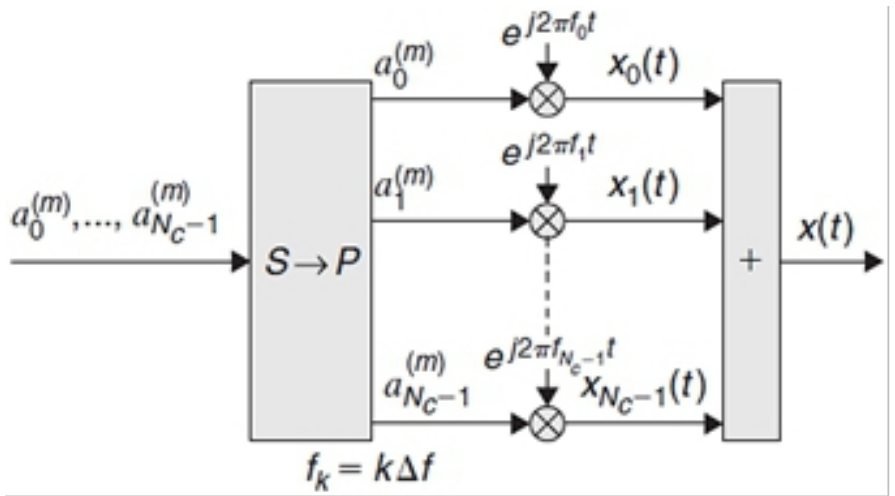

Figura 2. Modulador OFDM básico. (Tomado de (Dahlman et al., 2008))

El conjunto de subportadoras obtenidas se multiplexa en el tiempo para poder transmitirse sobre el mismo canal.

El circuito de la Figura 2 no resulta práctico, ya que se debe asegurar la estabilidad de los osciladores de radiofrecuencia para mantener la ortogonalidad de las subportadoras, y resulta costoso si se trabaja con un número elevado de éstas, entre otras razones. Sin embargo, la razón que permitió el amplio despliegue de OFDM fue el abaratamiento de la electrónica digital que permitió implementar en dispositivos VLSI el procesamiento digital de señales (DSP). En efecto, la señal OFDM resultante de la Figura 2 puede ser expresada como:

$$
\sum_{k=0}^{N_{c}-1} x_{k}(t)=\sum_{k=0}^{N_{c}-1} a_{k}^{m} e^{j 2 \pi k \Delta f t}
$$

Si esta señal se muestrea con una frecuencia $f_{m}=N \Delta f=N / T_{s}$ (lo que equivale a tomar $N$ muestras de señal en cada período de símbolo $T_{s}$ ), se tiene (Agusti et al., 2010):

$$
s[k]=\sum_{n} \sum_{\mu=0}^{M-1} A_{\mu}[n] g_{\mu}[k-n M] g_{\mu}[k]=\frac{1}{\sqrt{M}} \exp \left(\mathrm{j} 2 \pi \frac{\mu k}{M}\right)
$$




$$
x_{n}=x\left(n T_{m}\right)=\sum_{k=0}^{N_{c}-1} a_{k} e^{j 2 \pi k \Delta f n T_{m}}=\sum_{k=0}^{N_{c}-1} a_{k} e^{j 2 \pi k n / N}=\sum_{k=0}^{N-1} a_{k}^{\prime} e^{j 2 \pi k n / N}
$$

donde: $\quad a_{k}^{\prime}=\left\{\begin{array}{cc}a_{k} & 0 \leq k \leq N_{c} \\ 0 & N_{c} \leq k \leq N\end{array}\right.$

La secuencia $x_{n}$ es el inverso de la transformada discreta de Fourier (IDFT, Inverse Discrete Fourier Transform) de tamaño $N$ del bloque de los símbolos de la modulación a $0, \ldots \mathrm{a}_{\mathrm{Nc}-1}$ extendido con ceros a la longitud $N$ (Dahlman et al., 2008). Por lo tanto, la forma más simple de generar una modulación OFDM es considerar los $N_{c}$ símbolos a modular como los valores de las muestras en frecuencia de la señal resultante (a razón de una muestra por subportadora) y a partir de dichos símbolos calcular la IDFT de $N$ muestras. Si a su vez $N$ se hace igual a una potencia de dos, el proceso de cálculo puede acelerarse mediante el uso de la transformada rápida de Fourier inversa (IFFT - Inverse Fast Fourier Transform) (Agusti et al., 2010) y proporcionará las muestras temporales de la señal que finalmente se pasará por un conversor Digital/Analógico (D/A) para generar la señal analógica a transmitir (Figura 3).

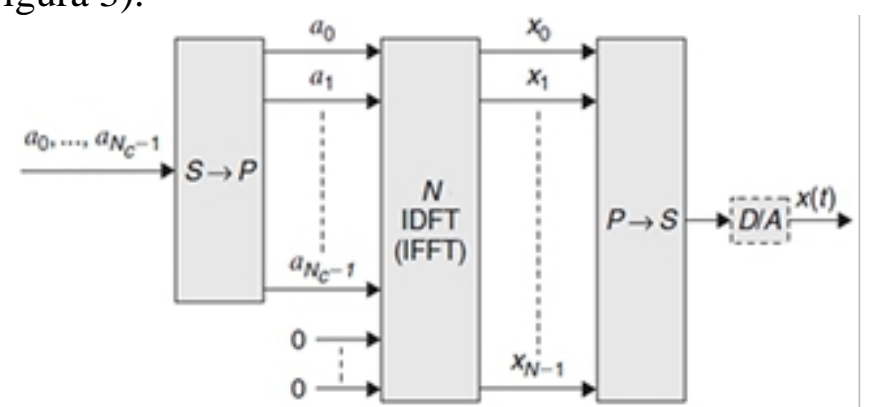

Figura 3. Modulador OFDM práctico. (Adaptado de (Dahlman et al., 2008))

En el demodulador, la recuperación de la señal se realiza mediante los procesos inversos, haciendo ingresar la señal recibida a $N_{c}$ ramas diferentes, en cada una de las cuales se aplica la multiplicación compleja por la correspondiente subportadora seguida de una integración en el período de símbolo (Figura 4a), o en forma práctica, utilizando la transformada rápida de Fourier (FFT) (Figura 4b). 


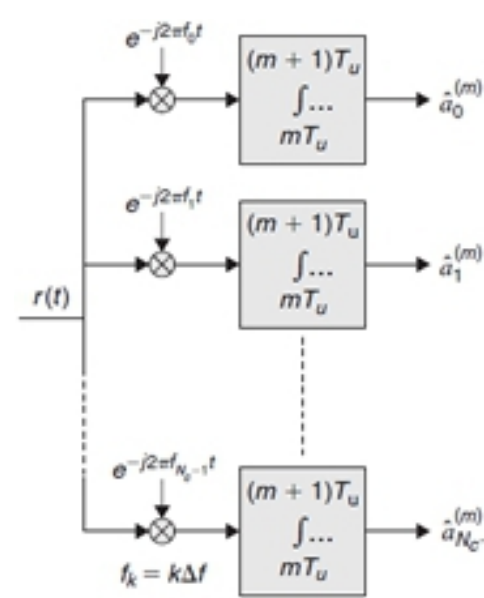

a)

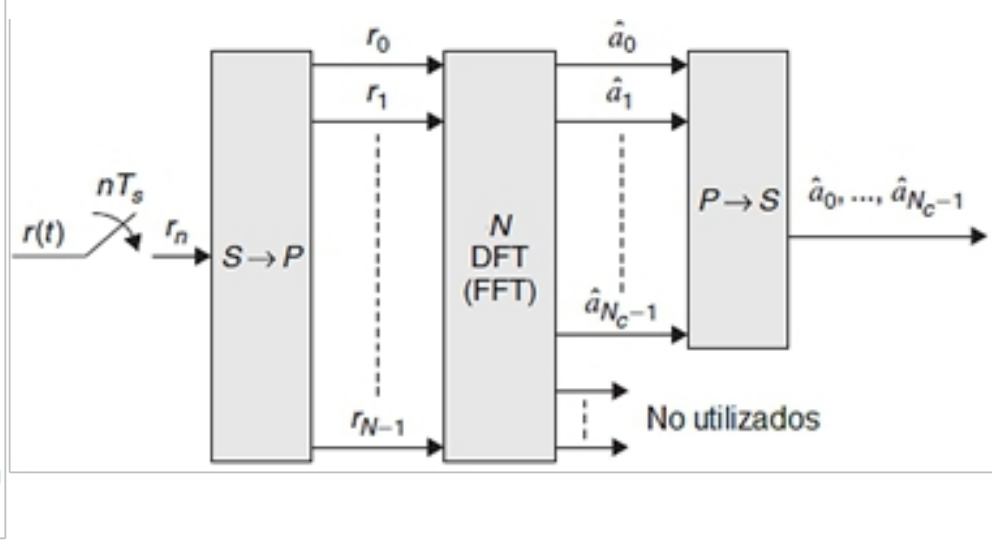

b)

Figura 4. Demodulador OFDM - a) básico; b) práctico. (Adaptado de (Dahlman et al., 2008))

\subsubsection{Prefijo cíclico}

No obstante, las ventajas analizadas de OFDM respecto a modulaciones simples, existen dos efectos indeseados introducidos por las características no ideales del canal. En primer lugar, la existencia de multitrayecto puede provocar que varias copias de la señal transmitida lleguen al receptor en tiempos diferentes, provocando interferencias de amplitud y fase entre símbolos, efecto conocido como interferencia inter símbolo (ISI). En segundo lugar, en canales variables en el tiempo, la ortogonalidad entre portadoras puede ser afectada, al producirse retardos variables para cada frecuencia. En consecuencia, aparece el efecto de interferencia entre portadoras (ICI, Inter Carrier Interference).

Para eliminar el ISI, se inserta un tiempo de guarda con una duración más larga que la duración de la respuesta de impulso del canal. Sin embargo, en presencia de canales dispersivos de tiempo lineal, un tiempo de guarda apropiado evita el ISI pero no el ICI. Para evitar este último, es necesario extender cíclicamente la duración del símbolo OFDM. Esto se logra, luego del procesado IFFT, haciendo que un segmento al final del símbolo OFDM de duración mayor que el máximo retardo introducido por el canal se copie al inicio del mismo, como se representa en la Figura 5 y 6 . En este caso, el tiempo de guarda se convierte en el prefijo cíclico (CP). 


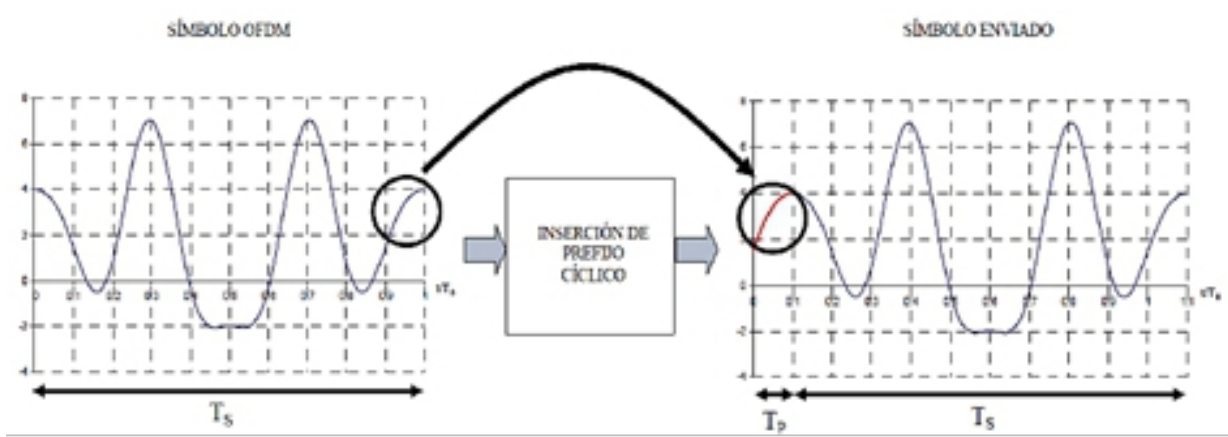

Figura 5. Copia e inserción del prefijo cíclico (tomado de (Agusti et al., 2010))

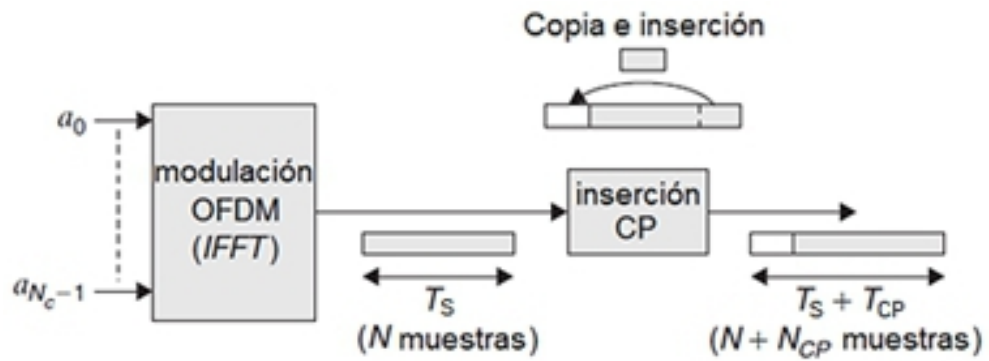

Figura 6. Proceso de generación del prefijo cíclico (adaptado de (Dahlman et al., 2008))

La inserción de un apropiado tiempo de guarda prolongado cíclicamente elimina ISI e ICI en un canal dispersivo lineal; sin embargo, produce una menor eficiencia de la potencia transmitida, ya que solo la fracción $T_{s} /$ $\left(T_{\mathrm{CP}}+T_{s}\right)$ de la potencia se destina a la parte útil de los símbolos, o lo que es lo mismo, introduce una pérdida en la relación señal / ruido (SNR) dada por

$$
\mathrm{SNR}_{\text {pércida }}(\mathrm{dB})=10 \log \frac{T_{\mathrm{S}}}{T_{\mathrm{S}}-T_{\mathrm{CP}}}
$$

Al mismo tiempo, provoca un aumento del ancho de banda necesario dado por

$$
\varepsilon_{B}=\frac{T_{\mathrm{S}}}{T_{\mathrm{S}}-T_{\mathrm{CP}}}
$$

y una disminución de la tasa de transmisión a $1 /\left(T_{s}+T_{\mathrm{CP}}\right)$ en lugar de $1 / T_{\mathrm{S}}$ si no se usara el CP (Hrasnica et al., 2005), (Agusti et al., 2010). Por lo tanto, la elección de la longitud del prefijo cíclico debe realizarse cuidadosamente. Su duración debe ser suficiente para superar la máxima dispersión del retardo de canal; en general, se adoptan valores cercanos al $10 \%$ del $T_{s}$ (ver Tabla 1).

\subsubsection{Realización de un sistema OFDM}

Un esquema típico de un sistema OFDM se muestra en la Figura 7: 


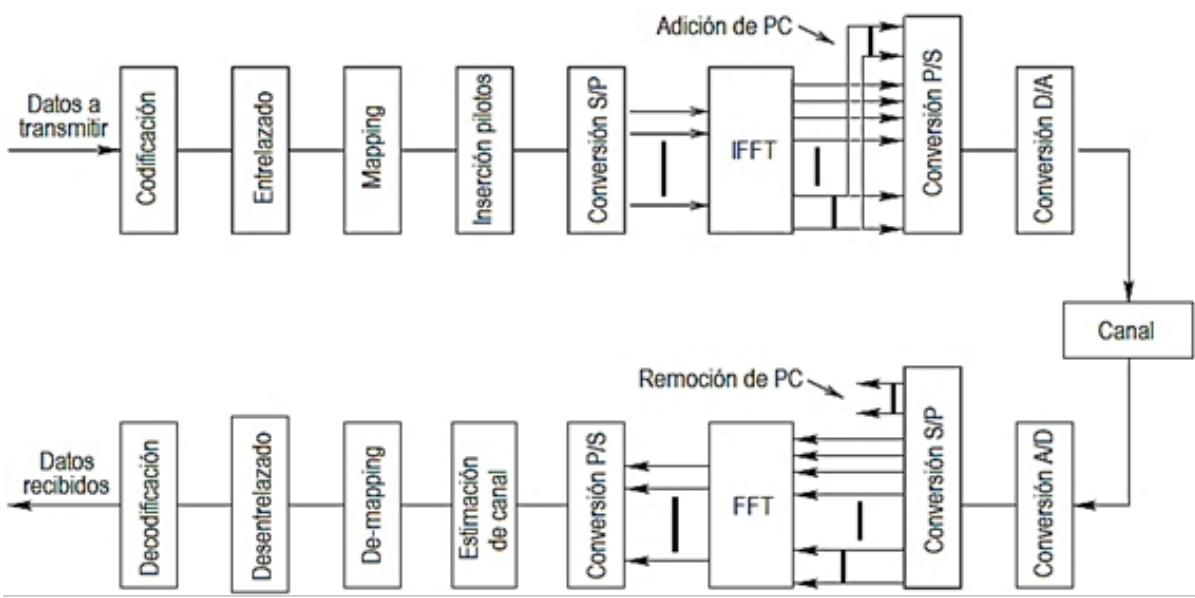

Figura 7. Realización de un sistema OFDM típico (adaptado de (Hrasnica et al., 2005))

En el diagrama, se observa que antes del proceso descripto en los puntos anteriores deben preceder varias operaciones sobre los bits de información antes de que se envíen al procesamiento de IFFT. Estas pueden resumirse en (Hrasnica et al., 2005).

\subsubsection{Codificación y entrelazado}

En términos generales, es inevitable la ocurrencia de errores en la transmisión, debido a las distorsiones originadas por el canal. La codificación de la información original y el entrelazado o intercalado (interleaving) se aplican a los bits de información a fin de proveer mecanismos que permitan corregir tales errores en el receptor o hacer más eficiente tal procedimiento. Estas funciones serán analizadas con detalle en el siguiente capítulo.

\subsubsection{Mapeo y codificación diferencial / no diferencial}

Como se explicó, los bits se agrupan en símbolos complejos, cuyos valores reales e imaginarios dependen de la técnica de codificación en banda base utilizada. Después de la codificación y el intercalado, los bits que se transportarán en el $l$-ésimo intervalo de tiempo OFDM y sobre la sub portadora $k$-ésima OFDM se mapean a un símbolo de modulación $S_{l, k}$. Este mapeo puede llevarse a cabo con o sin codificación diferencial. Sin codificación diferencial, los bits de datos se asignan directamente a los símbolos de modulación complejos. Con la codificación diferencial, los bits de datos no se mapean directamente a los símbolos de modulación complejos $S_{l, k}$, sino al cociente $B_{l, k}$ de dos símbolos de modulación complejos sucesivos, ya sea en la dirección temporal o en la dirección de frecuencia (Hrasnica et al., 2005). Si la codificación es en la dirección del tiempo, será

$$
S_{l, k}=S_{l-1, k} \times B_{l, k}
$$


y para inicializar este proceso de mapeo diferencial, cada subportadora del primer símbolo OFDM transmite un valor de referencia conocido. Si la codificación se realiza en la dirección de la frecuencia, entonces

$$
S_{l, k}=S_{l, k-1} \times S_{l, k}
$$

y para la inicialización de esta codificación diferencial, la primera subportadora de cada símbolo OFDM transmite un valor de referencia conocido.

En el receptor, y antes del desintercalado y la decodificación, el símbolo de modulación recibido $R_{l, k}$ se elimina del mapa para producir los bits transportados en el $l$-ésimo intervalo de tiempo OFDM y el $k$-ésimo sub canal OFDM. De acuerdo con el esquema de mapeo utilizado en el transmisor, se utiliza detección coherente o detección diferencial. Para el mapeo sin codificación diferencial, se emplea la detección coherente, por lo que la decisión se basa en el cociente $D_{l, k}$, dado por

$$
D_{l, k}=\frac{R_{l, k}}{\hat{H}_{l, k}} \approx S_{l, k}+\frac{N_{l, k}}{\hat{H}_{l, k}}
$$

donde $H_{l, k}$ es una estimación del factor de transferencia de canal $H_{l, k}$ y $N_{l, k}$ es el componente del aditivo blanco ruido gaussiano superpuesto al símbolo transmitido. Tal estimación es necesaria para identificar las referencias de amplitud y fase de la constelación en cada subportadora OFDM de modo que los símbolos de datos complejos puedan demodularse correctamente. Esta simple operación de ecualización representa la principal ventaja de los receptores OFDM. Esencialmente al transmitir los datos originales sobre múltiples subportadoras de banda estrecha, el canal global selectivo de frecuencia se transforma en un conjunto de canales de desvanecimiento plano cuyo efecto es solo introducir un desplazamiento aleatorio de atenuación/fase en cada subportadora OFDM. Por lo tanto, un ecualizador de canal OFDM corresponde a un banco de multiplicadores complejos.

En el caso de la codificación diferencial, la detección diferencial debe usarse en la recepción para recuperar los símbolos modulados. Si la codificación diferencial se hizo en la dirección del tiempo, entonces la detección diferencial se realiza comparando la información en la misma subportadora en símbolos OFDM consecutivos y la decisión se basa en el cociente:

$$
D_{l, k}=\frac{R_{l, k}}{R_{l-1, k}}=\frac{S_{l-1, k} B_{l, k} H_{l, k}+N_{l, k}}{S_{l-1, k} H_{l-1, k}+N_{l-1, k}}
$$

Si la codificación diferencial se realizó en la dirección de la frecuencia, entonces la detección diferencial se realiza comparando la información en subportadoras consecutivas en el mismo símbolo OFDM y la decisión se basa en el cociente: 


$$
D_{l, k}=\frac{R_{l, k}}{R_{l, k-1}}=\frac{S_{l, k-1} B_{l, k} H_{l, k}+N_{l, k}}{S_{l, k-1} H_{l, k-1}+N_{l, k-1}}
$$

Comparando ambos métodos de detección, los esquemas diferenciales son muy robustos a los desplazamientos de fase residual causados por un desplazamiento de sincronización de símbolo o un bloqueo de fase no perfecto entre el oscilador del transmisor y su correspondiente del receptor. Además, los esquemas diferenciales son realizables mediante implementaciones de receptor más simples porque no es necesaria una estimación de canal, en contraste con los no diferenciales. Sin embargo, en presencia de ruido, la detección diferencial muestra una degradación de hasta 3 dB en la SNR en comparación con la detección coherente ideal.

\subsubsection{Inserción de pilotos y estimación del canal}

En el caso del sistema de detección coherente, se necesita una estimación de canal. Esta estimación es importante para identificar la amplitud y la fase de cada subportadora recibida, de modo que los símbolos de datos complejos se puedan interpretar correctamente. La estimación del canal en sistemas OFDM requiere la inserción de símbolos conocidos o estructura piloto en la señal OFDM. Estos símbolos conocidos producen estimaciones puntuales de la respuesta de frecuencia del canal y una operación de interpretación que produce los puntos restantes de la respuesta de frecuencia del canal a partir de las estimaciones puntuales. El rendimiento del estimador depende en gran medida de cómo se transmite la información del piloto.

En general, los pilotos se disponen en una estructura bidimensional en tiempo y frecuencia, procurando una densidad de pilotos tal que permita obtener una representación precisa del canal. Esencialmente, el tiempo de coherencia del canal dicta la separación mínima de los pilotos en la dirección del tiempo y el ancho de banda de coherencia del canal dicta la separación mínima de los pilotos en el dominio de la frecuencia. Cuanto mayor es la densidad de los símbolos piloto, mejor es la precisión. Sin embargo, esto desmejora la SNR y la velocidad de datos.

\subsection{OFDM con procesamiento Wavelet (W-OFDM)}

El procesamiento de OFDM mediante la Transformada Discreta de Fourier (DFT), también denominada F-OFDM, es mayoritaria en la investigación y ha llegado a formar parte de los estándares que utilizan OFDM, en todas las bandas de frecuencia y en todos los medios físicos, debido a las variadas ventajas que posee en relación con las modulaciones monoportadora. Sin embargo, posee algunas desventajas (Galli et al., 2008):

- Como se apuntó, requiere un Intervalo de Guardia (GI) adecuado para eliminar el ISI. 
- Se caracteriza por malas propiedades espectrales que causan un alto grado de fuga espectral (la magnitud de las componentes de frecuencia fuera del lóbulo principal).

- Tiene una pobre capacidad de rechazo a la interferencia de banda estrecha (NBI) y poca resistencia al ruido impulsivo.

Como una alternativa a F-OFDM y en respuesta a las debilidades apuntadas, existe mucha investigación sobre un procesamiento de señales OFDM mediante la utilización de las llamadas wavelets ${ }^{14}$ ("ondículas"), implementándose a través de la Transformada Discreta Wavelet (DWT). El desarrollo ha llegado al punto de que Wavelet OFDM (W-OFDM o DWMT, Discrete Wavelet Multitone) ha llegado a ser parte de un estándar para la capa PHY de BB-PLC, como lo es el IEEE 1901.1 (Hoch, 2010) (Baig \& Yazdani, 2012).

W-OFDM se basa en la implementación de OFDM mediante bancos de filtros de reconstrucción perfecta modulados por coseno (PR-CMFB), que son realizaciones de transformadas wavelets, en contraposición a las funciones de base exponencial de F-OFDM (Hoch, 2010). Los bancos de filtros wavelet permiten la reconstrucción perfecta sin aliasing utilizando bancos de filtros no ideales (Baig \& Yazdani, 2012), que pueden implementarse con baja complejidad computacional (Galli et al., 2008).

\subsubsection{Comparación de W-OFDM con F-OFDM}

En F-OFDM, los pulsos de transmisión son secuencias con una ventana rectangular en el dominio del tiempo (Hoch, 2010), es decir, las formas de onda de símbolos utilizadas en OFDM no se superponen en el tiempo (Galli et al., 2008) (en el dominio de la frecuencia, las sub bandas adyacentes se superponen ortogonalmente, sin causar interferencia entre ellas). En el caso de W-OFDM, la longitud de los filtros utilizados es mayor que la del símbolo a trasmitir; por lo tanto, los pulsos de los símbolos consecutivos se superponen, pero pueden separarse en el banco de filtros del

${ }^{14}$ Una wavelet es una señal bien ubicada tanto en frecuencia como en tiempo, esto es, una oscilación de una frecuencia determinada y duración determinada (“ondita”). Un conjunto de wavelets se construye a partir de la denominada wavelet madre $\psi 0(\mathrm{t})$, y se obtiene mediante la dilatación o contracción de la misma, de acuerdo a un parámetro de escala "a". Este parámetro de escala representa la relación entre la frecuencia central de la wavelet madre y la wavelet derivada, y por este motivo en un análisis wavelet, se habla de dominio de las escalas en lugar de dominio de las frecuencias. Por otra parte, la wavelet se puede desplazar en una cantidad $\tau$, $\psi \mathrm{a}(\tau$-t) permitiendo lograr de manera simultánea (escala/tiempo) la adecuada ubicación de cualquier detalle que se quiera analizar en una señal. (Scappini, 2010). 
receptor sin ninguna interferencia, siempre que el canal de transmisión no introduzca ninguna distorsión (Hoch, 2010). Esto significa que las señales en el tiempo sí están superpuestas. La cantidad de solapamiento (número de símbolos consecutivos superpuestos) viene determinada por un parámetro $g$, que es la relación entre la longitud del filtro y el número de sub bandas. Esto provoca las siguientes diferencias entre ambos tipos de procesamiento.

\subsubsection{Características espectrales}

El uso de símbolos de mayor duración en W-OFDM permite obtener niveles inferiores de lóbulo lateral con respecto al F-OFDM. Una mejor atenuación de la banda de atenuación da como resultado niveles más bajos de interferencia entre canales (ICI) y mayor robustez a las interferencias de banda estrecha.

La Figura 8 muestra la característica de espectro de F-OFDM convencional (para una banda BB-PLC). Como muestra la figura, en los lóbulos laterales OFDM convencionales caen a lo sumo $13 \mathrm{~dB}$ bajo el lóbulo principal, lo que origina una fuga espectral. Esta limitación se puede mejorar con una técnica de "enventanado" (windowing), reemplazando la ventana rectangular habitual con otras más elaboradas, y permitiendo lograr mejores características espectrales que las OFDM convencionales. La ventana se aplica al símbolo OFDM individual, con el objetivo de hacer que la amplitud tienda a cero en los límites del símbolo (Galli et al., 2008). Esta técnica tiene varias limitaciones. En primer lugar, aumenta considerablemente la complejidad computacional. En segundo lugar, en el caso de PLC, la ventana debe realizarse tanto en el transmisor (para obtener muescas profundas y no ocupar bandas no permitidas), como en el receptor (para proporcionar robustez frente a NBI). En tercer lugar, las ventanas pueden bajar el segundo lóbulo lateral en el mejor caso de $-13 \mathrm{~dB}$ a $-20 \mathrm{~dB}$ debajo del lóbulo principal, lo que significa que es necesario suprimir varias sub portadoras para obtener muescas profundas. En cuarto lugar, la operación de enventanado causa un aumento de la longitud del intervalo de guardia, lo que provoca una mayor reducción de la eficiencia de transmisión del sistema.

W-OFDM no sufre los inconvenientes mencionados anteriormente. De hecho, la introducción de la superposición de símbolos permite más grados de libertad en la optimización de las características espectrales de W-OFDM. La Figura 8 b) muestra el PSD de W-OFDM para un caso con $g=4$. El W-OFDM simulado aquí exhibe $22 \mathrm{~dB}$ adicionales de banda de detención con respecto a F-OFDM, logrando una profundidad de muesca de alrededor de $-35 \mathrm{~dB}$. Por lo tanto, W-OFDM logra un rechazo de banda adyacente superior, una mejor resiliencia de NBI y una mejor eficiencia de transmisión que F-OFDM con enventanado (Galli et al., 2008). 


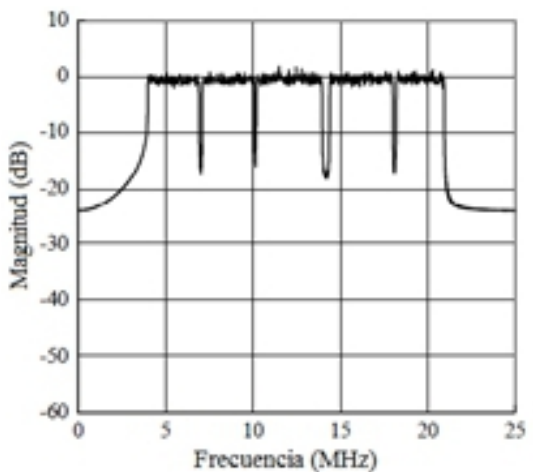

a)

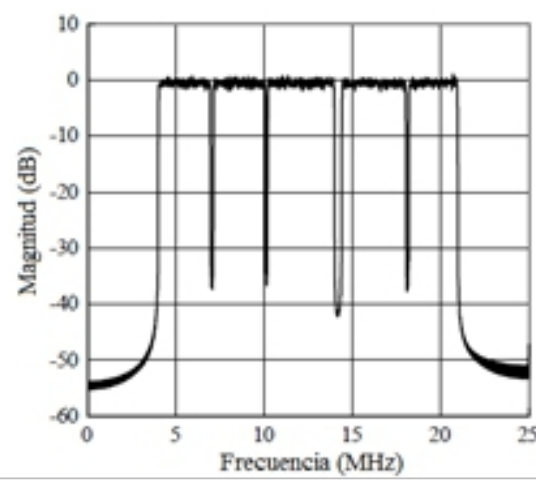

b)

Figura 8. Respuesta en frecuencia de sub bandas en a) F-OFDM y b) W-OFDM (Adaptado de (Koga et al., 2003))

\subsubsection{Cancelación de ISI}

La técnica utilizada en F-OFDM para compensar el ISI es emplear un intervalo de guarda que permite una ecualización simple en el receptor a costa de una pérdida en la eficiencia de la transmisión. Si el ISI no se cancela completamente, la capacidad de los sistemas F-OFDM para afrontar el ISI no compensado solo depende del recíproco del espaciamiento entre sub portadoras, ya que no hay superposición de símbolos.

En el caso de W-OFDM, como la duración del símbolo en se extiende sobre símbolos consecutivos, no se utiliza intervalo de guarda. Esto hace que, aunque el ISI no se elimina (o compensa), los sistemas W-OFDM sean más eficientes que los F-OFDM al no utilizar recursos adicionales. La resiliencia al ISI resulta entonces directamente proporcional a la duración del símbolo WOFDM, esto es, al recíproco del espaciamiento entre sub portadoras y al grado de solapamiento introducido por los bancos de filtros. Como aumentar $g$ causa una mayor complejidad computacional, lo que generalmente se hace en la práctica es aumentar el número de subportadoras. Por lo tanto, a diferencia de F-OFDM, en sistemas W-OFDM es posible obtener una mayor solidez a ISI al aumentar el número de sub portadoras (Galli et al., 2008).

La Figura 9 representa las diferencias fundamentales explicadas entre el procesamiento de F-OFDM (a), y W-OFDM (b). Si bien Wavelet-OFDM se desarrolló originalmente a partir de CMFB como punto de partida, puede describirse de una manera más general mediante un banco de filtros modulado exponencialmente (EMFB) permitiendo una banda base compleja equivalente (BCE), tal como se representa en la Figura 9 b). 


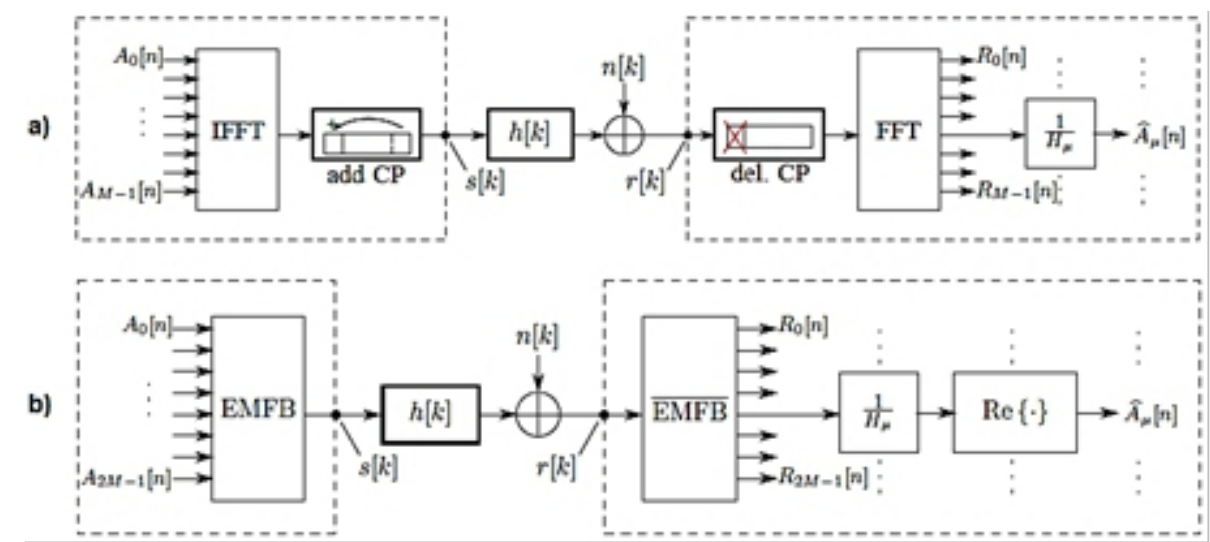

Figura 9. Esquema general de procesamiento en a) F-OFDM y b) W-OFDM (Tomado de (Hoch, 2010))

\subsubsection{Eficiencia espectral}

En cuanto a eficiencia espectral (la cantidad de información transmitida en el ancho de banda utilizado), ambas técnicas son equivalentes. F-OFDM utiliza modulaciones complejas, es decir, constelaciones 2D tales como QAM. En cambio, en los PR-CMFBs (o EMFBs), para que se cumpla la condición de ortogonalidad entre sub portadoras, los valores de los coeficientes solo pueden ser elegidos de constelaciones de números reales (1D), tales como PAM. Sin embargo, la resolución de frecuencia de W-OFDM es dos veces la de F-OFDM porque una permite un mayor grado de superposición espectral. Como consecuencia, para el mismo ancho de banda total y el mismo número de puntos de $\mathrm{N}, \mathrm{W}-\mathrm{OFDM}$ usa $\mathrm{N}$ portadoras reales mientras que OFDM usa N/2 portadoras complejas. Por lo tanto, OFDM y WOFDM tienen la misma eficacia espectral (Galli et al., 2008).

\subsubsection{W-OFDM para aplicaciones en NB-PLC}

Los trabajos de investigación citados como base de los puntos anteriores están orientados a aplicaciones en la banda BB-PLC. El hecho del desarrollo de un estándar para esa banda, el IEC 1901.1 citado precedentemente, junto con una gran cantidad de trabajos de investigación en los últimos años, confirma las ventajas analizadas en el punto anterior para W-OFDM.

Uno de los objetivos del presente trabajo es el análisis de la aplicación de W-OFDM a la banda NB-PLC. En principio, todas las bondades estudiadas para la banda BB-PLC son trasladables a NB-PLC. Sin embargo, en (Hoch, 2010), se analizan dos aspectos que relativizan esta conclusión preliminar.

En primer lugar, como consecuencia de la extensión de la duración de los símbolos como consecuencia de la traslación en el tiempo y superposición de éstos, existe una sobrecarga al final de una cadena de símbolos trasmitida, que puede valuarse como $g N /(S+g) N$, siendo $S$ el número de símbolos OFDM 
transmitidos en un paquete dado. Si la cantidad de símbolos por paquete es pequeña, como puede ser el caso en las aplicaciones en NB-PLC, la latencia del sistema puede degradarse significativamente. No obstante, esta sobrecarga debería evaluarse cuidadosamente con datos de tráfico concretos en aplicaciones específicas.

En segundo lugar, un aspecto más difícil de soslayar es el hecho de que, como se ve en el próximo punto, los estándares más difundidos en NB-PLC utilizan detección no coherente, como una forma de hacer más simples los receptores al evitar la estimación del canal (ver 3.2.2); y esto significa la utilización de codificación diferencial. Como se dijo, W-OFDM solo puede codificar constelaciones de valores reales; lo que implica que solo podría utilizar una codificación diferencial binaria (DBPSK, por ejemplo). Si bien esto ya es una limitación importante, (Hoch, 2010) demuestra que el receptor genera símbolos complejos, cuya parte imaginaria debe ser considerada un término de interferencia generada por varios símbolos de la secuencia; pero cuyo valor interviene numéricamente en el valor real del cual se debe extraer la información de fase o amplitud del símbolo a decodificar. En una modulación coherente, el sistema de estimación del canal corrige esa distorsión; en una modulación no coherente eso no ocurre, lo que lleva a que los símbolos recibidos contengan un error impredecible de magnitud $180^{\circ}$ en la información de rotación de fase. Este hecho hace inviable la aplicación de W-OFDM a modulaciones diferenciales, a la sazón, las más utilizadas en NBPLC.

\subsection{Estándares en NB-PLC}

En respuesta al interés de las compañías eléctricas y de comunicaciones en la utilización de PLC, los aspectos detallados en los puntos anteriores (y otros que se analizarán más adelante) han sido plasmados en un conjunto de especificaciones técnicas por parte de la industria, principalmente europea. A continuación, se resumen los aspectos salientes (desde el punto de vista del objetivo del proyecto) de uno estándares más desarrollados en el mercado, PRIME y se los comparan con los de las otras tres especificaciones más difundidas. Este análisis sirve de contexto en el que se definirá el modelo de comunicación propuesto en el punto 3.

\subsubsection{Ubicación de los estándares en el modelo de referencia ISO/OSI}

En relación con el modelo de referencia ISO/OSI, los estándares a analizar definen las especificaciones de las capas de enlace y física. En particular, para las especificaciones PLC a analizar, la capa de enlace se divide en dos subcapas (Hrasnica et al., 2005): LLC (Logical Link Control, control de enlace lógico) (subcapa superior), que procesa la detección y corrección de errores y el control del flujo de datos; y la MAC (Medium Access Control, 
control de acceso al medio) (subcapa inferior), que especifica los protocolos de acceso. La capa PHY (física), procesa la transmisión de bits a través del canal, incluyendo las características físicas, la sincronización, la codificación, la modulación, etc.

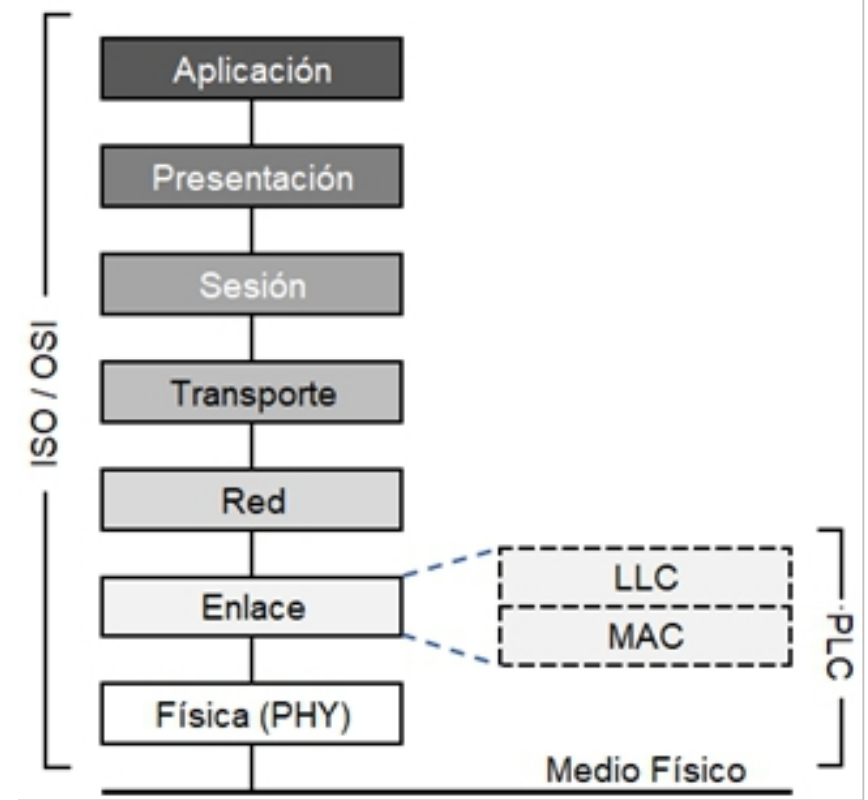

Figura 10. Estructura de capas - Modelo ISO/OSI / PRIME (adaptado de (Hrasnica et al., 2005))

\subsubsection{Principales especificaciones}

Debido a que los estándares y recomendaciones a analizar comparten una estructura y elementos básicos muy similares, se describirá en detalle uno de ellos (PRIME) y en relación con él se marcarán las características principales de los restantes.

La alianza PRIME (PoweRline Intelligent Metering Evolution) surgió en 2009, de un grupo de fabricantes liderada principalmente por la empresa española Iberdrola. La idea era proporcionar una especificación abierta para un transceptor PLC en la banda CENELEC-A. Actualmente, la solución PRIME alcanza su mayor difusión principalmente en España, Portugal y el Reino Unido. Desde el año 2012 ha sido incluido dentro de las especificaciones de la ITU, en la Recomendación ITU-T G.9904.

El transceptor PRIME hace uso del espectro entre 42 y $89 \mathrm{kHz}$ para insertar símbolos OFDM, con el formato de la Figura 11. La trama incluye una señal del preámbulo utilizada con fines de sincronización y estimación del canal; una cabecera de dos símbolos con información; y finalmente los datos provenientes de la capa MAC, encapsulados en una carga útil (payload) de una longitud de hasta $\mathrm{M}=63$ símbolos. 


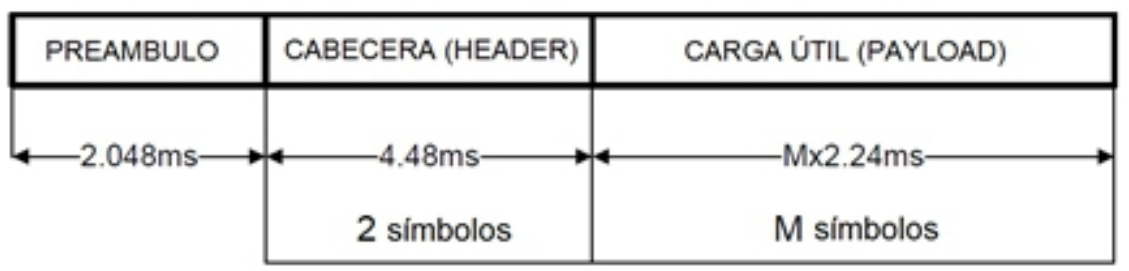

Figura 11. Formato de trama PHY en PRIME (adaptado de (PRIME, 2013))

Cada uno de estos símbolos consta de 97 sub portadoras ubicadas en el ancho de banda mencionado, según la distribución espectral de la Figura 12. En la carga útil, uno de estos operadores es un piloto con la misión de dar una referencia de fase para el receptor. En el caso del encabezado, el número de pilotos se incrementa a 13 y están destinados a estimar el desplazamiento de frecuencia de muestreo y la referencia de fase para las sub portadoras de datos.

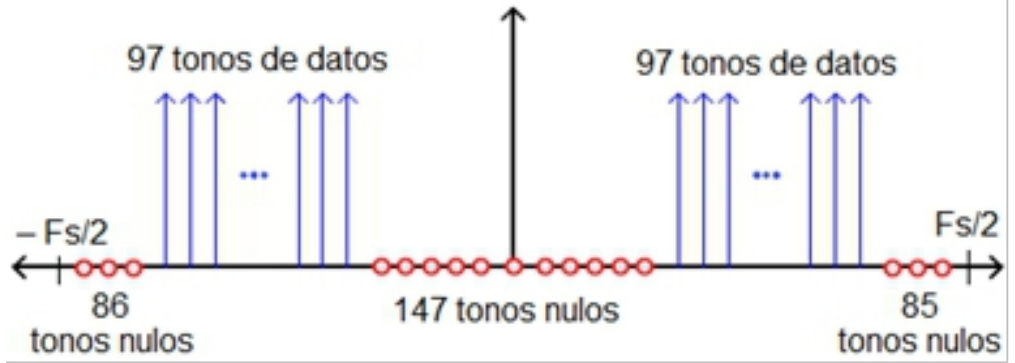

Figura 12. Espectro de frecuencias en PRIME (adaptado de (Matanza, 2013))

Para construir dicho espectro, se utiliza una frecuencia de reloj de 250 $\mathrm{kHz}$ y una IDFT de 512 de longitud, lo que da un espaciado de sub portadora de $\Delta \mathrm{f}=250 \mathrm{kHz} / 512=488,28125 \mathrm{~Hz}$. Las sub portadoras presentes en frecuencias negativas y positivas se conjugan entre sí de modo que la salida del bloque de Transformada Discreta Inversa de Fourier (IDFT) es una señal real pura (Figura 13).

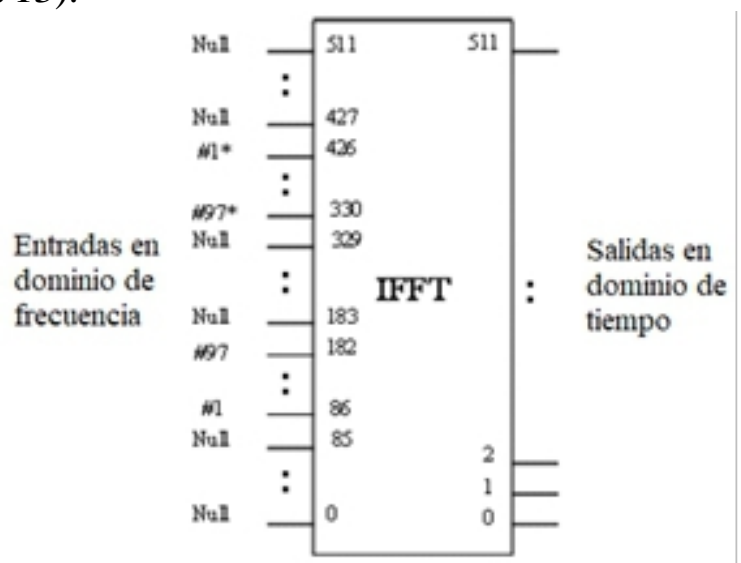

Figura 12. Estructura de subportadoras en PRIME (adaptado de (PRIME, 2013)) 
El esquema de transmisión completo está representado en la Figura 13. A la salida del bloque IFFT se realiza una extensión de prefijo cíclico de 48 muestras, y luego de la conversión de paralelo a serie, modulación analógica de la señal.

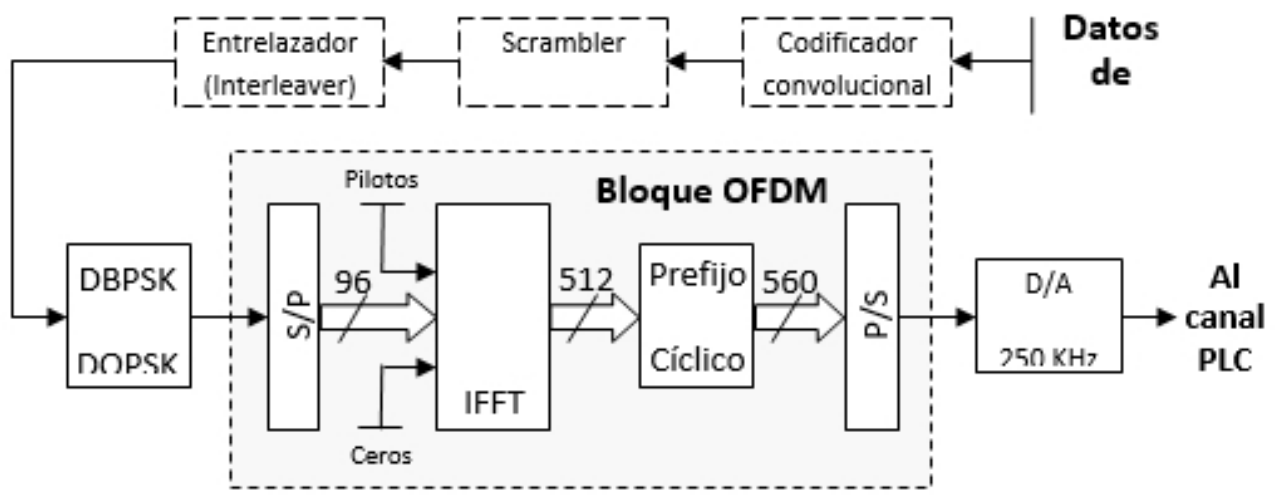

Figura 13. Formato PRIME (adaptado de (Matanza, 2013))

Los datos se modulan con una modulación Diferencial de Desplazamiento de Fase (DPSK). La carga útil puede modularse con una constelación DBPSK, DQPSK o D8PSK (Diferencial Binario / Cuadratura / Octal, respectivamente). Los bloques anteriores (marcados en trazo discontinuo en la Figura 13 son los encargados de proveer la codificación de la información y la manipulación de los bits utilizadas para optimizar la señal a transmitir y proveer de herramientas para superar las condiciones adversas del canal. Estas funciones se presentarán y discutirán en el capítulo siguiente.

La Tabla 1. compara los principales parámetros de la especificación PRIME (ITU-T G.9904) con G3-PLC (ITU-T G.9903), G.hnem (ITU-T G.9902), y la IEEE 1901.2.

\begin{tabular}{|l|c|c|c|c|}
\hline \multicolumn{1}{|c|}{ Párametro } & PRIME & G3-PLC & P1901.2 & G.hnem \\
\hline Frecuencia de reloj (Fs) & $250 \mathrm{KHz}$ & $400 \mathrm{KHz}$ & $400 \mathrm{KHz}$ & $200 \mathrm{KHz}$ \\
\hline $\begin{array}{l}\text { Espaciamiento entre } \\
\text { subportadoras }(\Delta \mathrm{f})\end{array}$ & $488,28125 \mathrm{~Hz}$ & $1.562,5 \mathrm{~Hz}$ & $1.562,5 \mathrm{~Hz}$ & $1.562,5 \mathrm{~Hz}$ \\
$\begin{array}{l}\text { Número de portadoras de } \\
\text { datos (en carga útil) }\end{array}$ & 96 & 36 & 36 & 33 (máx.) \\
$\begin{array}{l}\text { Número de portadoras pilotos } \\
\text { (en carga útil) }\end{array}$ & 1 & 0 & 0 & 3 \\
\hline $\begin{array}{l}\text { Tamaño FFT } \\
\text { Muestras del prefijo cíclico }\end{array}$ & $512(2.048 \mu \mathrm{s})$ & $256(640 \mu \mathrm{s})$ & $256(640 \mu \mathrm{s})$ & $128(640 \mu \mathrm{s})$ \\
$\begin{array}{l}\text { Duración del símbolo OFDM } \\
\text { (FFT + prefijo cíclico) } \\
\text { Duración del preámbulo }\end{array}$ & $2.240 \mu \mathrm{s}$ & $22(192 \mu \mathrm{s})$ & $22(192 \mu \mathrm{s})$ & $24(120 \mu \mathrm{s})$ \\
\hline
\end{tabular}

Tabla 1. Parámetros de los estándares más utilizados en la banda CENELEC-A (adaptado de (Matanza, 2013)) 
Si bien existen varios aspectos a analizar, es interesante notar la diferencia de la duración del prefijo cíclico, $(2048 \mu$ s en PRIME vs. $\sim 6000 \mu$ s en los otros estándares), lo que refleja las dificultades para lograr un modelo uniforme en la estimación de los parámetros del canal PLC (en este caso la dispersión máxima del retardo), según se explicó en 3.2.2 (Matanza, 2013).

\section{Modelo propuesto para la simulación}

El transceptor propuesto se basa en los estándares mencionados. Utiliza una modulación OFDM FFT en DQPSK, y configura el símbolo según la estructura de PRIME, de quien también se toman el tamaño del prefijo cíclico y la frecuencia de muestreo. El esquema completo se representa en la Figura 25.

El sistema no incluye las funciones de codificación, entrelazado y scrambler de los estándares, ya que la codificación será objeto de la propuesta a desarrollar en el próximo capítulo.

Dado que cada bloque funcional del transmisor se corresponde con uno que realiza la función inversa en el receptor, se describen ambos en conjunto.

\subsection{Modulador / demodulador banda base}

Los datos binarios provenientes de la capa MAC, previo paso por el codificador que se desarrollará en el capítulo siguiente, ingresan al bloque modulador o "mapper" DQPSK del transmisor, configurado con un código Gray y offset nulo (Figura 14), que genera el número complejo correspondiente al símbolo de dos bits ingresado:

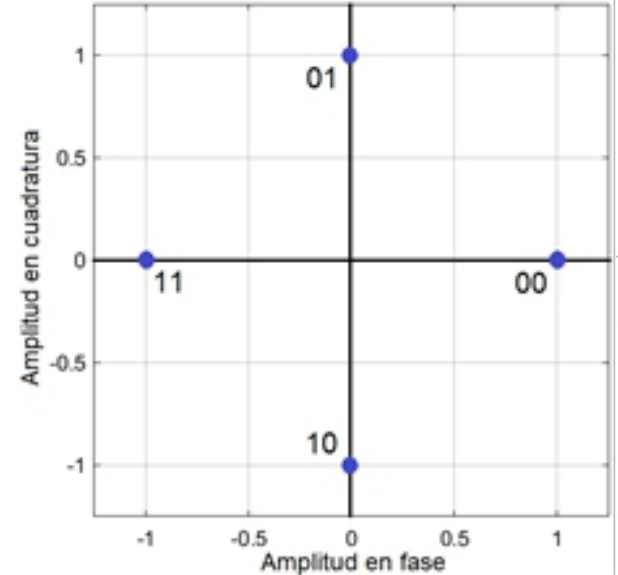

a)

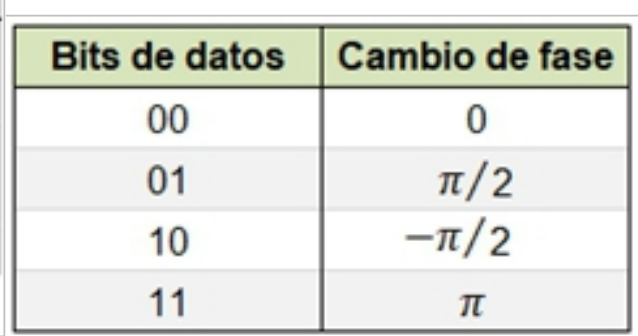

b)

Figura 14. Codificación DQPSK Gray utilizada - a) Constelación de símbolos b) Defasaje de cada símbolo respecto al anterior (Propio) 


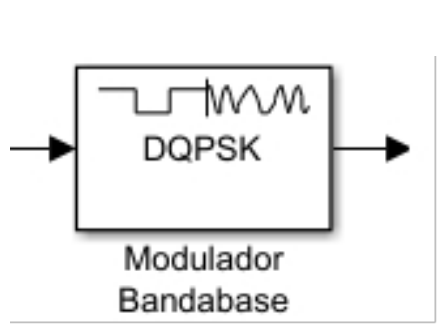

a)

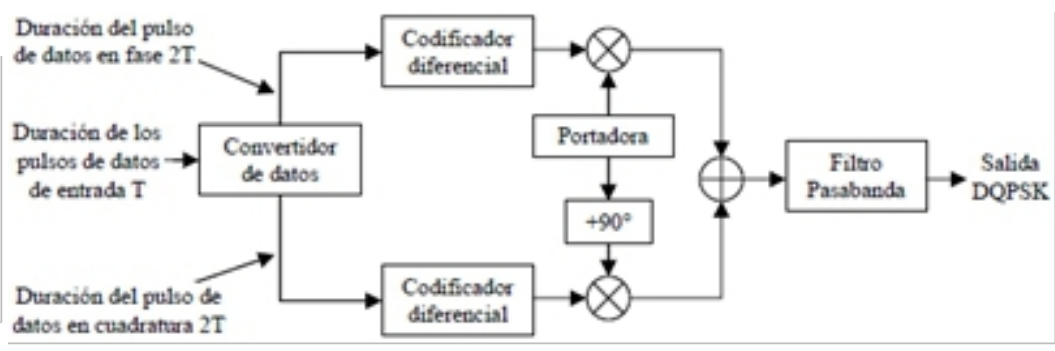

b)

Figura 15. a) Bloque modulador DQPSK; b) Esquema de modulación (Propio)

En el receptor, el bloque que realiza la función inversa es el demodulador DQPSK, que entrega los datos binarios al sistema de decodificación.

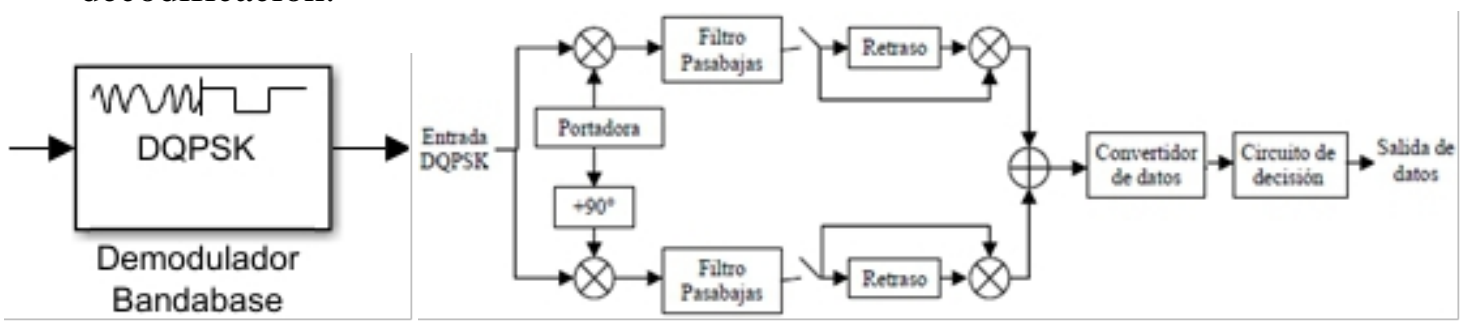

a)

b)

Figura 16. a) Bloque demodulador DQPSK; b) Esquema de demodulación (Propio)

\subsection{Bloque OFDM}

En el transmisor, los datos modulados ingresan al bloque que conforma el símbolo OFDM a utilizar. De acuerdo al esquema de PRIME utilizado, el bloque conforma los símbolos recibidos en el formato de la Figura 12, mediante el esquema de la Figura 17 b). Los valores de las constantes introducidos al vector resultante son ceros, de acuerdo a la especificación. El selector multi puerto agrupa 97 símbolos consecutivos (de los cuales el primero es el piloto y los restantes 96 la información a ser transmitida en cada símbolo OFDM), los duplica y concatena con la cantidad de símbolos nulos correspondientes al formato de la Figura 12 en el vector resultado. 


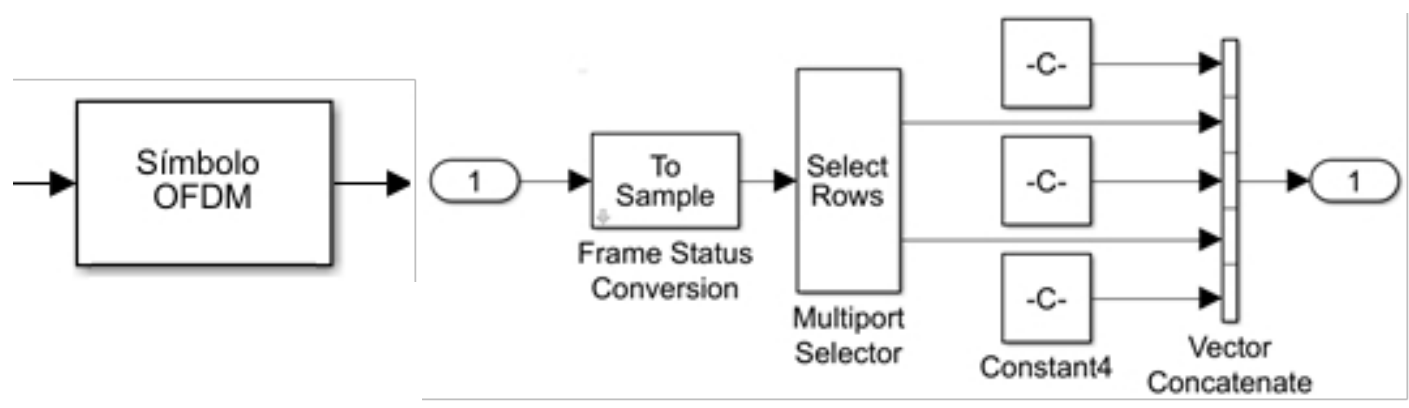

a)

b)

Figura 17. a) Bloque Símbolo OFDM; b) Bloques componentes (Propio)

En el receptor, el bloque de recuperación del símbolo OFDM extrae los 97 símbolos originales de la señal recibida.

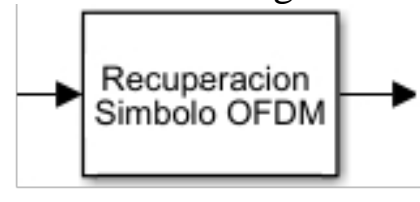

a)

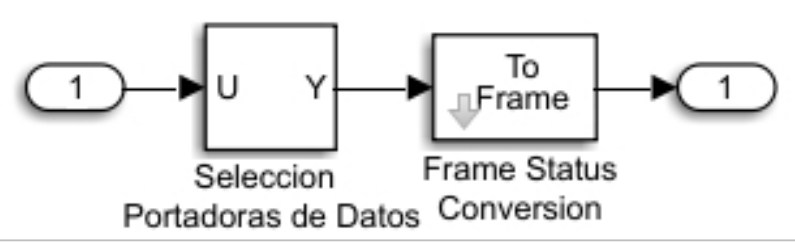

b)

Figura 18. a) Bloque Recuperación de Símbolo OFDM; b) Bloques componentes (Propio)

\subsection{Bloques IFFT / FFT}

El siguiente bloque del transmisor (Figura 19) en el receptor realiza la transformada rápida inversa de Fourier (IFFT), trasladando los símbolos del dominio de la frecuencia al domino temporal. A continuación, se seleccionan los 48 últimos y se copian al principio de la secuencia, conformando el prefijo cíclico. Por último, el vector resultante se transforma en una cadena en serie, mediante una conversión paralelo/serie.

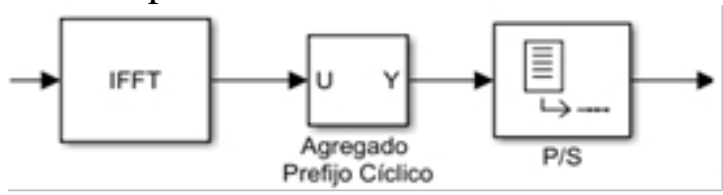

Figura 19. Bloque IFFT e inserción del prefijo cíclico (Propio)

En el receptor (Figura 20), se produce la conversión serie a paralelo de los datos recibidos, se extrae el prefijo cíclico y se realiza la transformada rápida de Fourier, devolviéndolos al dominio de la frecuencia.

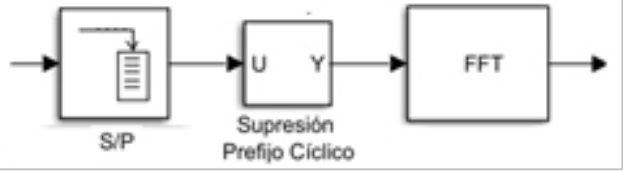

Figura 20. Supresión del prefijo cíclico y bloque FFT (Propio) 


\subsection{Bloques modulador / demodulador pasa banda}

Para su inserción en el simulador del canal físico, en el transmisor la señal se sobre muestrea en un factor de 10 y se filtra utilizando un filtro de respuesta finita (FIR) (bloque Interpolación FIR, Figura 21 a), modulándose luego con la frecuencia de $250 \mathrm{KHz}$ (Figura 22).

En el receptor, se demodula la señal analógica (Figura 23), y se filtra y sub muestrea en un factor de 10 en el bloque Decimación FIR (Figura 21b).

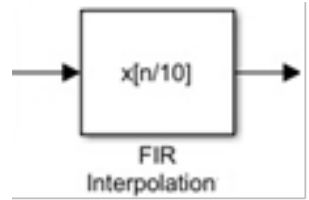

a)

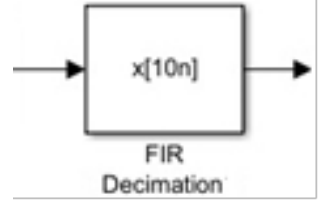

b)

Figura 21. a) Bloque Interpolación FIR; b) Bloque Decimación FIR (Propio)

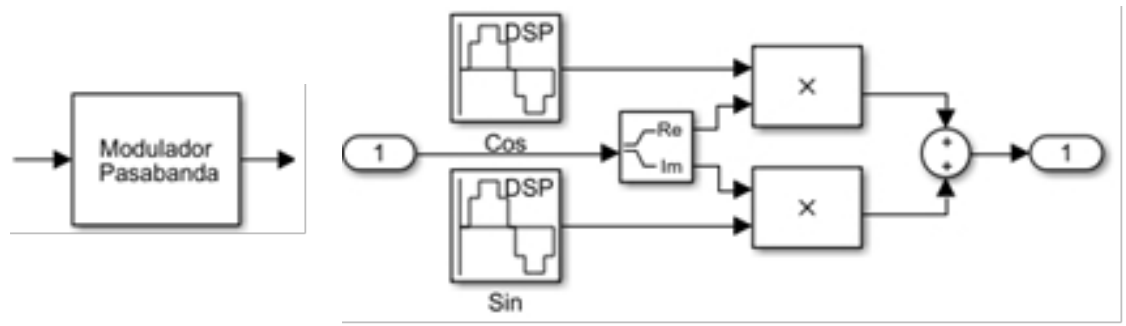

a)

b)

Figura 22. a) Bloque Modulador pasa banda b) Esquema de modulación (Propio)

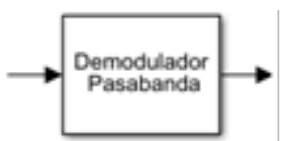

a)

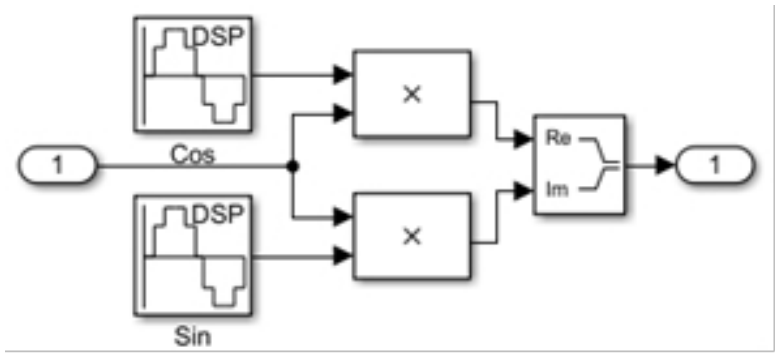

b)

Figura 23. a) Bloque Modulador pasa banda b) Esquema de modulación (Propio)

\subsection{Cálculo del error}

La tasa de error se registra con el bloque correspondiente, a partir de los bits transmitidos y los recibidos (Figura 24). 


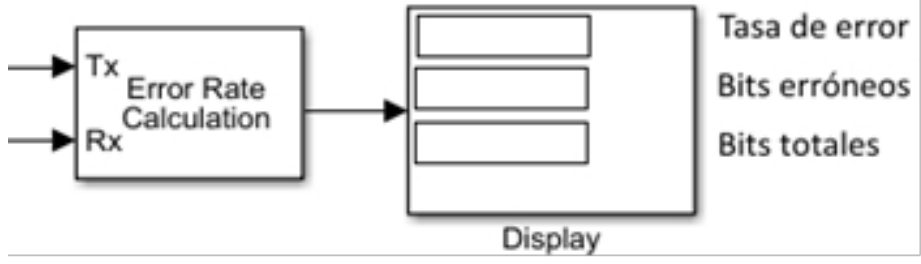

Figura 24. Bloque de cálculo y visualización de la tasa de error de bits (Propio)

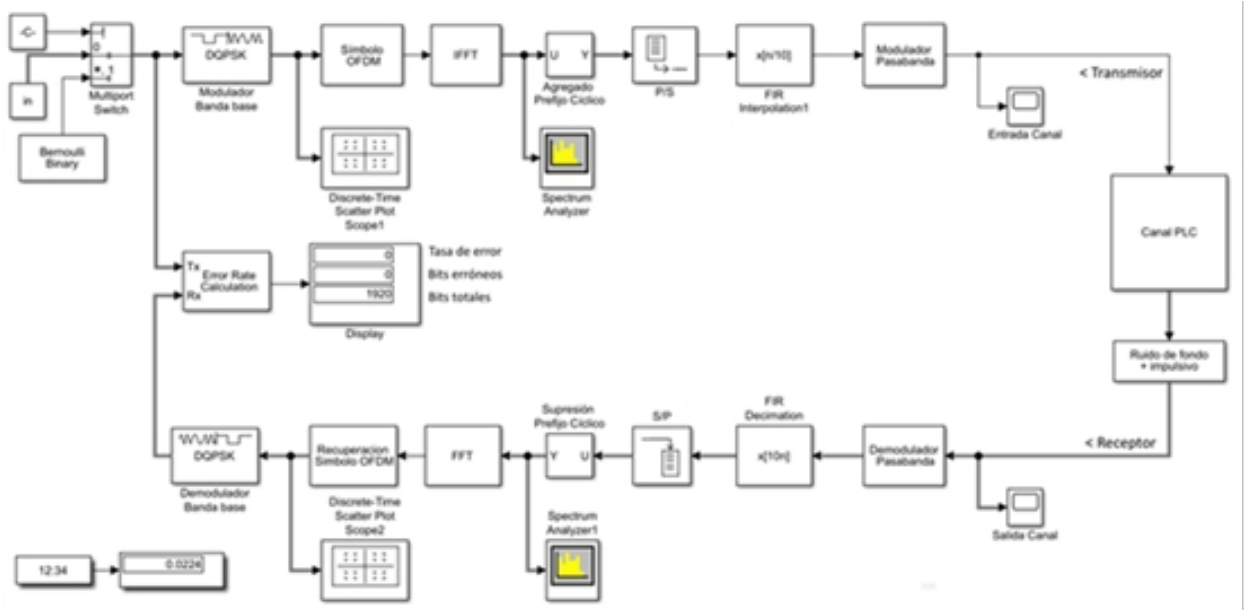

Figura 25. Modelo del transmisor / receptor (Propio)

\section{Resultados}

El modelo propuesto se simula inyectando una sucesión de símbolos $(00$; $01 ; 11 ; 10$ ) en el canal presentado en (Veglia et al., 2018), con condiciones de ruido de fondo e impulsivo cercanas a cero. En esas condiciones se verificó en las que el modelo recupera en el receptor sin errores la información transmitida, es decir, con BER $=0$.

Las figuras 26 y 27 muestran los gráficos de densidad espectral de potencia (PSD) de las señales obtenidas a la salida del bloque IFFT en el transmisor y a la entrada del FFT en el receptor, respectivamente, para la secuencia de símbolos anterior.

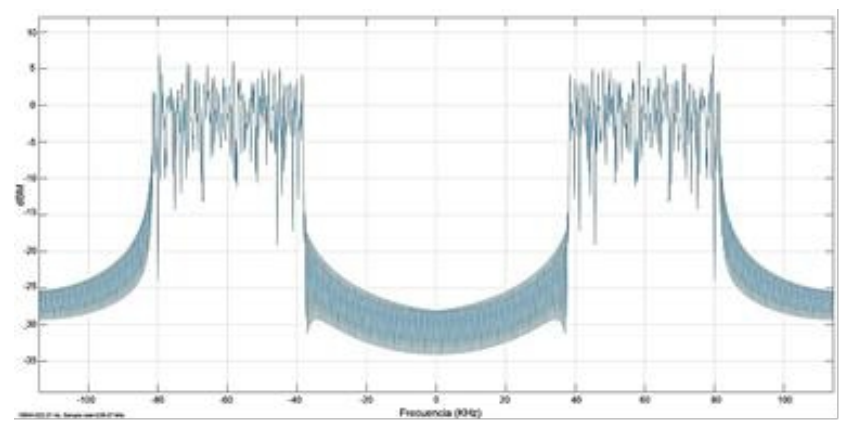

Figura 26. PSD de la señal a la salida del bloque IFFT (Propio) 


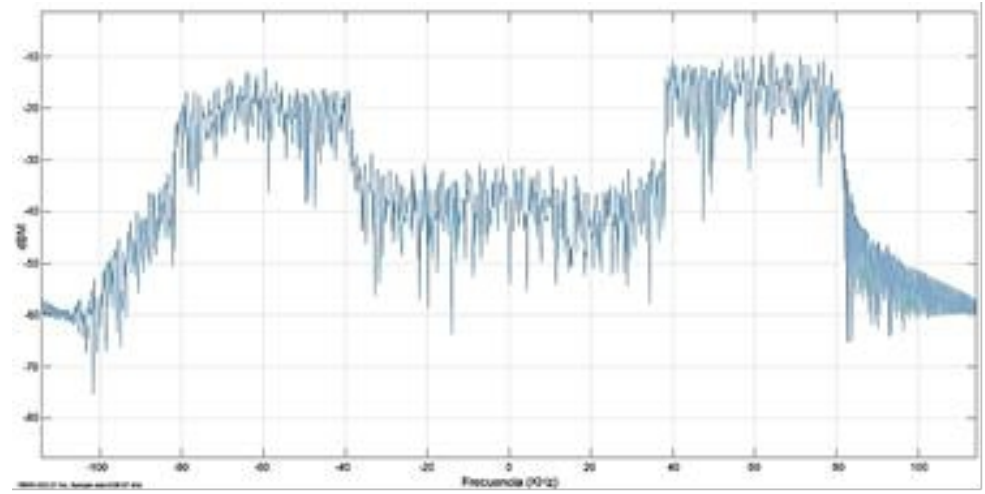

Figura 27. PSD de la señal a la entrada del bloque FFT para condiciones de canal sin ruido. (Propio)

\section{Conclusiones}

El modelo obtenido implementa un transceptor basado en la especificación PRIME, en cuanto a sus frecuencias de operación, configuración espectral, longitud de trama y cantidad de subportadoras. Utiliza una modulación diferencial, por lo cual, como se explicó, presenta la limitación de que solo puede ser procesado mediante la transformada discreta de Fourier.

En la entrada y en la salida del transceptor presentado es posible ensayar esquemas de codificación/decodificación, que provean robustez frente al ruido introducido en el canal.

Como se muestra en el punto 4 se obtuvieron resultados satisfactorios en cuanto a la recuperación de la señal sin errores, aplicando ruido acorde al modelo de canal (Veglia et al., 2018), modelo desarrollado en el ámbito de este estudio y publicado con anterioridad

Como trabajo futuro, teniendo en cuenta lo expuesto en los puntos 2.2.1 a 2.2.5, el modulador puede ser cambiado por uno no diferencial, lo que permitiría con cambios, ensayar un procesamiento mediante DWT (Transformada Wavelet Discreta).

\section{References:}

1. Agusti, R., Bernardo, F., Casadevall, F., Ferrús, R., Pérez-Romero, J. \& Sallent, O. (2010). Nuevas Tendencias en Comunicaciones Móviles. España: Fundación Vodafone, ISBN: 84-934740-4-5.

2. Baig, S. \& Yazdani, J. (2012 marzo 5). Performance analysis of discrete wavelet multitone transceiver for narrowband PLC in Smart Grid 2011 2nd IEEE PES International Conference and Exhibition on Innovative Smart Grid Technologies, Manchester, 2011, pp. 1-6. doi: 10.1109/ISGTEurope.2011.6162767 (2018 sep 6) IEEE Xplore. 
3. Dahlman, E., Parkvall, S., Sköld, J. \& Beming, P. (2008). " $3 G$ Evolution: HSPA and LTE for Mobile Broadband, 2nd edition, Academic Press - Elsevier, Oxford, UK, ISBN: 978-0-12-374538-5.

4. Galli, S., Koga, H. \& Kodama, N. (2008 abril 2). Advanced signal processing for PLCs: Wavelet-OFDM," 2008 IEEE International Symposium on Power Line Communications and Its Applications, Jeju City, (2018 sep 6), pp. 187-192. IEEE Xplore.

5. Hoch, M. (2010). Comparison of ConvOFDM and Wavelet-OFDM for Narrow-Band Power Line Communications. 2018 sep 6, de ResearchGate Sitio web: https://www.researchgate.net/publication/228896148_Comparison_of ConvOFDM_and_Wavelet-OFDM_for_Narrow-

Band_Power_Line_Communications

6. Hrasnica, H., Haidine, A. \& Lehnert, R. (2005 july 1). Broadband Powerline Communications Networks: Network Design. USA: John Wiley \& Sons, Ltd ISBN:9780470857410 |Online ISBN:9780470020920.

7. Koga, H., Kodama, N. \& Konishi, T. (2003). High-speed Power Line Communication System based on Wavelet OFDM. 7th International Symposium of Power-Line Communications and Its Applications, Kyoto, Japan, Session B5: OFDM, 26-28. (2018 sep 6), De Semantic Scholar Base de datos.

8. Matanza, J. (2013 octubre 25). Improvements in the PLC Systems for Smart Grids Environments, Tesis Doctoral. Universidad Pontificia Comillas. Madrid (España). 2018 septiembre 6, De Universidad Pontificia Comillas. Madrid.

9. Scappini, R.J.R. (2010 agosto 22). Estudio del Tráfico Autosimilar Orientado a la Simulación Mediante la Utilización de Wavelets u Onditas, Tesis Magistral. 2018 septiembre 6, de Universidad Nacional de La Plata - Argentina Sitio web: http://sedici.unlp.edu.ar/handle/10915/4179.

10. PRIME Alliance Technical Working Group. (2013). Draft Specification for Power line Intelligent Metering Evolution. 6 septiembre 2018, de PRIME Alliance Technical Working Group Sitio web: https://www.prime-alliance.org/wpcontent/uploads/2013/04/PRIME-Spec_v1.3.6.pdf .

11. Veglia, J. E., La Red Martinez, D. \& Scappini, R.J.R. (a publicar diciembre de 2018). Simulación de un Canal PLC para AMI para Empresas Distribuidoras de Energía Eléctrica con Fines Didácticos y de Investigación. International Journal of Information Systems and Software Engineering for Big Companies (IJISEBC), Vol 5, Num 2. 